\title{
THE INFLUENCE OF PURCHASING ORIENTATIONS, ONLINE TRUST AND ONLINE PURCHASE EXPERIENCE TOWARD CUSTOMERS' ONLINE PURCHASE INTENTION
}

Nasrul Fadhrullah Isa*

Arshad Ayub Graduate Business School

Universiti Teknologi MARA (UiTM), Sabah

Malaysia

nasrulfadhrullahisa@gmail.com

\section{Imelda Albert Gisip}

Faculty of Business and Management

Universiti Teknologi MARA (UiTM), Sabah

Malaysia

imeldag@uitm.edu.my

\section{Sharifah Nurafizah Syed Annuar}

Faculty of Business and Management

Universiti Teknologi MARA (UiTM), Sabah

Malaysia

Shari339@sabah.uitm.edu.my

\section{Nelson Lajuni}

Faculty of Business, Economics and Accountancy

Universiti Malaysia Sabah (UMS)

Malaysia

nelsonl@ums.edu.my

*Corresponding author's email: nasrulfadhrullahisa@gmail.com

Peer-review under responsibility of 4th Asia International Multidisciplinary Conference 2020 Scientific Committee http://connectingasia.org/scientific-committee/ (C) 2020 Published by Readers Insight Publisher, Office \# 6, First Floor, A \& K Plaza, Near D Watson, F-10 Markaz, Islamabad. Pakistan, editor@readersinsight.net This is an open access article under the CC BY-NC-ND license (http://creativecommons.org/licenses/by-nc-nd/4.0/). 


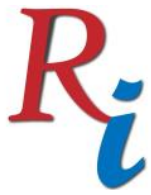

\section{Asia Proceedings of Social Sciences (APSS) \\ www.readersinsight.net/APSS}

\section{A b s t r a c t}

The study examines the factors influencing customers' online purchasing intentions. The data were collected from university students $(n=584)$ through a structured Partial Least SquaresStructural Equation Modeling (PLS-SEM) approach to examine the proposed study hypotheses. The PLS-SEM approach has been revealed that except for brand orientation, all the other variables exert significant influences on the online purchasing intention of customers in Malaysia. The impulse purchase orientation was seen to have a significant impact on the online purchase intention of customers. This was followed by an online purchase experience, and then online trust and quality orientation. The results possess explanatory and predictive capacity to predict online purchase intention among university students in Malaysia. This research is helpful to online retailers, marketing managers, online vendors and policymakers in the development of business strategies. It can be beneficial to the community and also the academicians to conduct further research by adding a new variable in the mix for generation and evolution of the concept. The originality of the study is its examination of the determinants as the predictors under the suggested theoretical framework and the Decomposed Theory of Planned Behaviour (DTPB) as the underlying theory for this study. The findings underpin fresh insights into strategic marketing and the development of emergent literature on consumer purchasing intention in online shopping in Malaysia.

Keyword: Online Purchase Intention; Purchasing Orientations; Online Trust; Online Purchase Experience

\section{Rese a r ch H i g h I igh t s}

- The research study can potentially benefit the following breakdown of the importance to online retailers, marketing managers, Internet marketers, online vendors, policymakers, academicians, community, and industry.

- Consumer education is a crucial factor in keeping the economy going, i.e., Online purchasing, information, purchase decision, consumer culture, etc.

- The shoppers' familiarity with the significant job that online business has played in present-day data innovation (IT) can be upgraded.

- There is not enough research to use the TPB model to talk about the expectation of buying online in contrast with notable conventional TRA.

- The specialist recommends that breaking down the conviction constructs into multidimensional constructs expands our comprehension of these connections.

- From a business perspective, online buy has become increasingly essential and is extensively acknowledged. Therefore, how to assemble, keep up, and improve client connections is a significant issue in a savagely severe condition. 


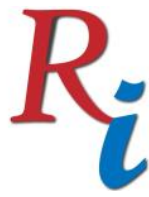

\section{Asia Proceedings of Social Sciences}

(APSS)

www.readersinsight.net/APSS

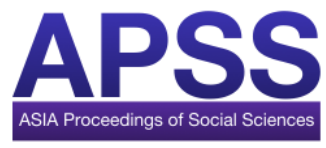

- The consequences of this examination show that it would be a considerable technique for advertisers to re-evaluate how to teach potential clients and advance online buys utilizing development qualities. That will offer what is to come to a vital research field.

\section{Rese arch Frame work}

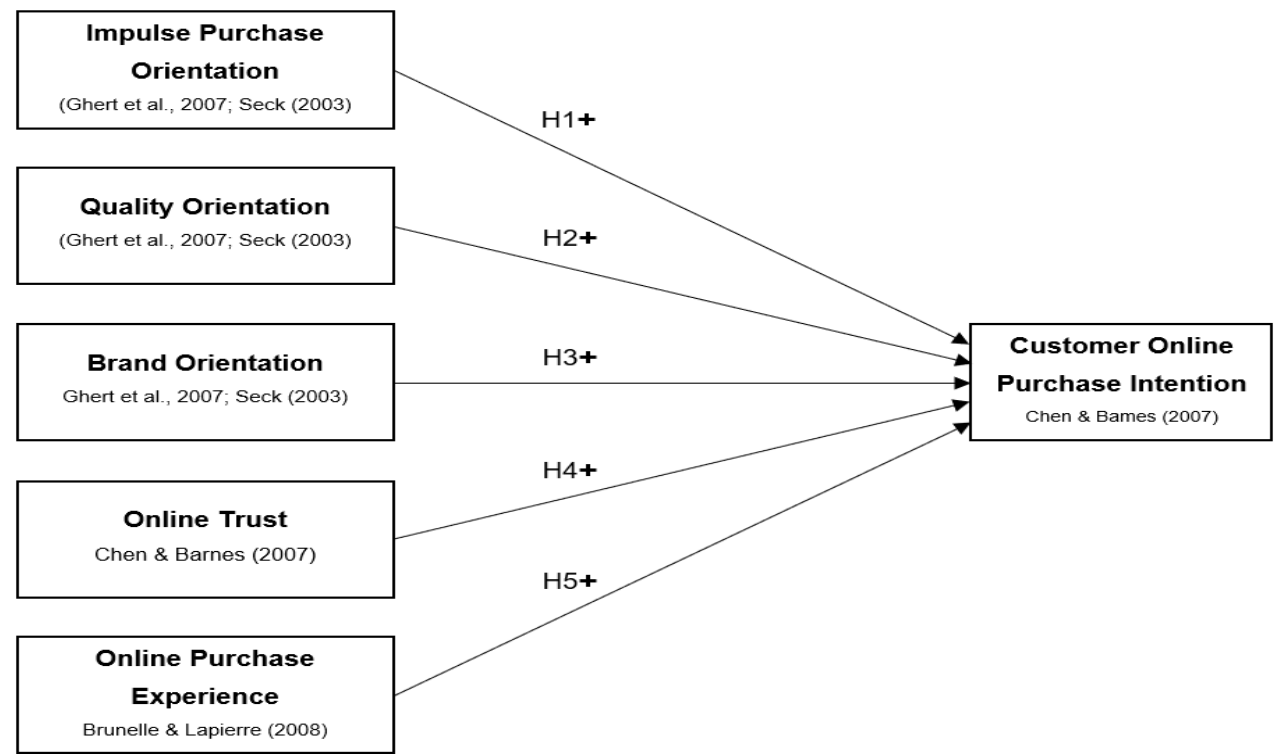

Fig. 1. Research Framework

Source: Developed for the research by the author

\section{Me a surement Model Assessment}

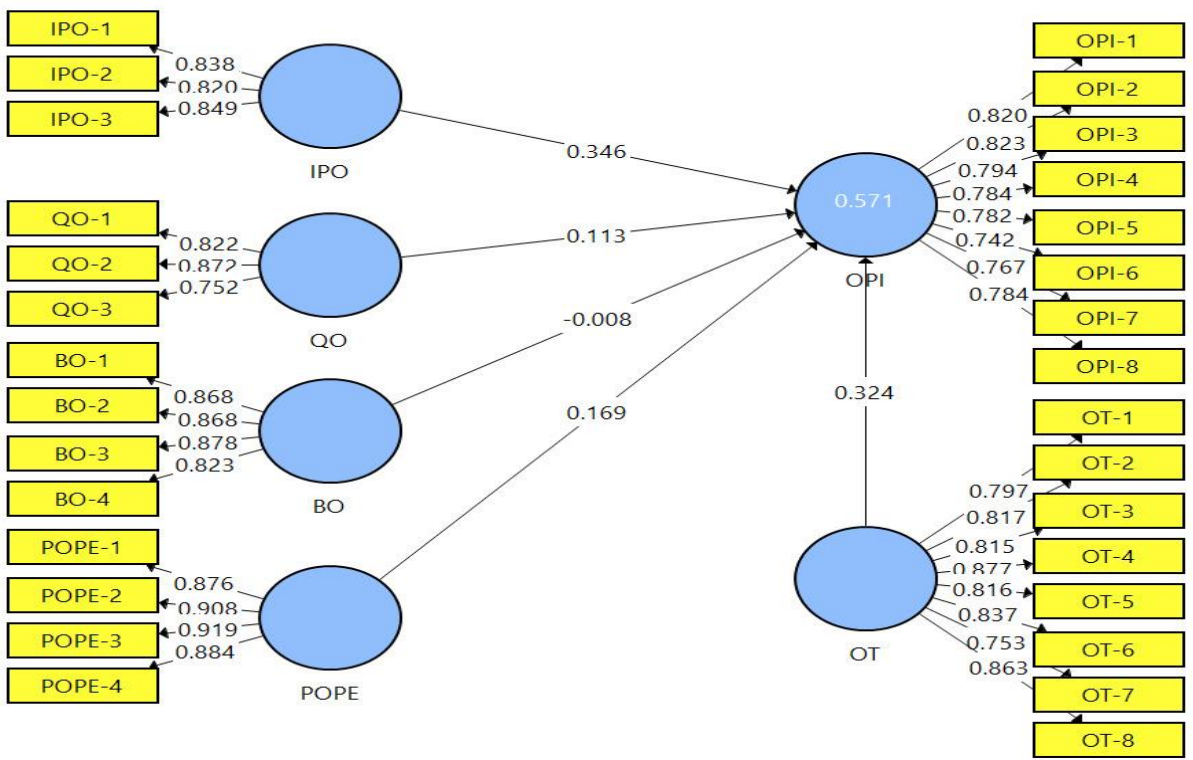

Fig. 2. Measurement Model Assessment 


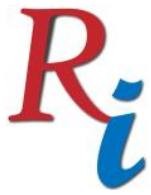

\section{Asia Proceedings of Social Sciences}

(APSS)

www.readersinsight.net/APSS

\section{Structural Model Assessment}

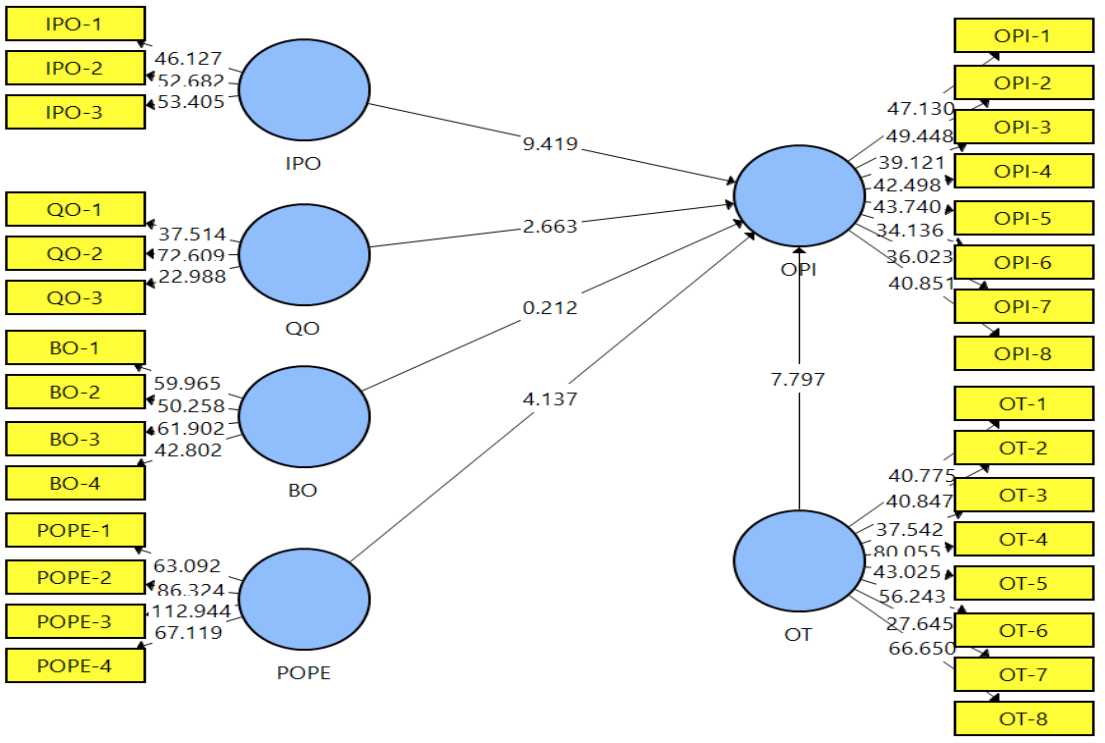

Fig. 3. Structural Model Assessment

\section{Research Objectives}

There is a various school of thoughts on the research objective. For this study, it will segregate the general-purpose into specific research objectives:

1. To examine the influence of impulse purchase orientation on online purchasing intention among Malaysian university students.

2. To examine the influence of quality orientation on online purchasing intention among Malaysian university students.

3. To examine the influence of brand orientation on online purchasing intention among Malaysian university students.

4. To examine the influence of online trust on online purchasing intention among Malaysian university students.

5. To examine the influence of online purchase experience on online purchasing intention among Malaysian university students.

\section{Methodology}

This study used online surveys that relay Google Forms links to respondents through the platform such as email, direct link, embedding, social media accounts, and WhatsApp Messenger. This allowed more than 700 respondents to be recruited for this study. The questionnaire was active for approximately two months, from January to February 2020, and incorporated 46 questions split into three sections. From this distribution, 584 usable responses were analyzed with a response rate of $83 \%$. The questionnaire was generated in English and 


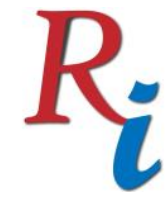

\section{Asia Proceedings of Social Sciences (APSS) \\ www.readersinsight.net/APSS}

Malay, and the questionnaire design also based on the literature review and the use of established measures. Demographic information such as gender, age, race, ethnicity, educational level, and income level requested in section A. Then, section B required responses concerning the online purchase experience. Lastly, the respondent's perception of online purchases was recorded in section $\mathrm{C}$. The items for the independent variables and dependent variable are adapted from Gehrt et al. (2007) \& Seock (2003), Chen \& Barnes (2007), and Brunelle \& Lapierre (2008). Each item was graded on a five-point Likert scales, where 5 indicates strong agreement, and 1 indicates the opposite. The collected questionnaires were screened and coded before entry to the IBM Statistical Package for the Social Science (IBM SPSS Statistics). The analysis was carried out using Partial Least Square-Structural Equation Modeling (PLS-SEM) in SmartPLS 3.0 (Hair et al., 2019).

\section{Results}

Hair et al. (2017) guidelines are used to assess the outer loadings of the factors, which resulted in no deletion of the item for any construct. The values obtained for Cronbach Alpha and Composite Reliability (Hair et al. 2010), for internal consistency, were estimated along with Convergent Validity for correlation among the constructs. All requirement was met as the reliability values are above 0.7 with no AVE lower than 0.5 (Hair, Hult, et al., 2014).

HTMT test for determining the discriminant validity (Ringle et al., 2015) of the latent variables based on HTMT 0.85 and HTMT 0.90 criterion. Thus, the researcher allowed to continue with the assessment of the structural model to evaluate the hypothesis of the analysis since the issues of multicollinearity are non-existent for the items on other model constructs. The result specifies that $\mathrm{HTMT}_{0.85}$ well establishes discriminant validity (Henseler et al., 2015).

The assessment of multicollinearity, as per Hair et al. (2017), is carried out by checking VIF values. The presence of high correlations amongst the independent variables constitutes multicollinearity. The values smaller than 3.3 mean that collinearity is not an issue (Diamantopoulos \& Siguaw, 2006). A further step was the measurement of path coefficients with a 5000-sample bootstrapping routine (Hair et al., 2017). The path coefficients for each relation in the conceptual framework are known as Beta values. The results of the structural model assessment show that four of the hypotheses are supported except for brand orientation, which does not impact online purchase intention.

The magnitude of the $\mathrm{R}^{2}$ as a criterion of predictive accuracy and the blindfolding procedure output $\left(\mathrm{Q}^{2}\right)$ exhibit the model's predictive relevance. The quality of the model is also depicted in the results with impulse purchase orientation, having a substantial impact on intention along with quality orientation. This is demonstrated by moderate and significant effect sizes $\left(\mathrm{f}^{2}\right)$. The predictive relevance values are greater than 0 for all constructs, indicating that independent variables are ideal for predicting the dependent variable as anticipated by $\mathrm{Q}^{2}$ following the blindfolding procedure laid out by Hair et al. (2017). 


\section{Findings}

1. The impulse purchase orientation was seen to have a significant impact on the online purchase intention of customers.

2. Online purchasing experience has a vital and robust effect on the purchase intention of consumers.

3. Individuals' online trust positively influences their purchasing intention.

4. Quality orientation has had a positive impact on customers' online purchasing intentions.

5. Brand orientation did not have a significant impact on consumers' online purchase intentions.

\section{Acknowledgement}

The authors would like to acknowledge the Universiti Teknologi MARA, Cawangan Sabah, Kota Kinabalu Campus. We also honour Arshad Ayub Graduate Business School and the Faculty of Business and Management, UiTM Sabah for valuable support for the research work.

\section{References}

Gehrt, K. C., Onzo, N., Fujita, K., \& Rajan, M. N. (2007). The emergence of Internet shopping in Japan: Identification of shopping orientation-defined segments. Journal of Marketing Theory and Practice, 15(2).

Seock, Y., \& Norton, M.J. (2003). Analysis of clothing websites for young customer retention based on a model of customer relationship management via the Internet.

Chen, Yu-Hui \& Barnes, Stuart. (2007). Initial trust and online buyer behaviour. Industrial Management and Data Systems. 107. 21-36. 10.1108/02635570710719034.

Brunelle, Eric \& Lapierre, Josée. (2008). Testing media richness theory to explain consumers' intentions of buying online. ACM International Conference Proceeding Series. 31. 10.1145/1409540.1409582.

Jr, Hair, \& Risher, Jeff \& Sarstedt, Marko \& Ringle, Christian. (2018). When to use and how to report the results of PLS-SEM. European Business Review. 31. 10.1108/EBR-112018-0203.

Hair, J.F., Hult, G.T.M., hairRingle, C.M., and Sarstedt, M. A Primer on Partial Least Squares Structural Equation Modeling (PLS-SEM), $2^{\text {nd }}$ Ed., Sage, Thousand Oaks, 2017.

Hair, Joseph \& Hult, G. Tomas M. \& Ringle, Christian \& Sarstedt, Marko. (2014). A Primer on Partial Least Squares Structural Equation Modeling. 


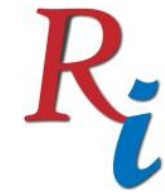

\section{Asia Proceedings of Social Sciences (APSS) \\ www.readersinsight.net/APSS}

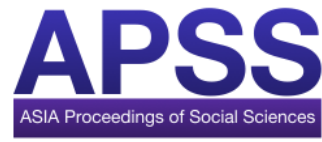

Henseler, Jörg \& Ringle, Christian \& Sarstedt, Marko. (2015). A New Criterion for Assessing Discriminant Validity in Variance-based Structural Equation Modeling. Journal of the Academy of Marketing Science. 43. 115-135. 10.1007/s11747-014-0403-8.

Diamantopoulos, Adamantios \& Siguaw, Judy. (2006). Formative Versus Reflective Indicators in Organizational Measure Development: A Comparison and Empirical Illustration. British Journal of Management. 17. 263 - 282. 10.1111/j.1467-8551.2006.00500.x.

\section{Author's Biography}

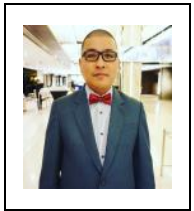

Nasrul Fadhrullah Isa is currently Technical Support Manager in Celcom Timur (Sabah) Sdn Bhd. With over 17 years in the private sector, manufacturing, and telecommunications industries, the author has previously held several technical and marketing-related positions. He is currently in the final year of his DBA in Marketing, focusing on Consumer Behaviour, Universiti Teknologi MARA (UiTM Sabah), Malaysia. Several of his contributions and recognitions; ROGE Oxford U.K. London, published in CBER (2019); Inventors' Hall of Fame (i-fame) Competition (2019); SIVIIC (2019); SCG Bangkok Business Challenge @Sasin (2020); ICGBEFSS (2020); Borneo Scientific Research Conference (2020), IJOA (2020); IJAST (2020), and AIMC 2020.

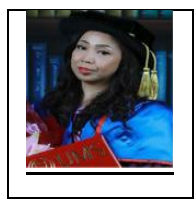

Imelda Albert Gisip is a Senior Lecturer at the Faculty of Business and Management, UiTM Sabah, Malaysia. She received her PhD in Marketing from Universiti Malaysia Sabah in 2016 and currently serves as the Coordinator, Strategic Planning \& Information Unit, Universiti Teknologi MARA (UiTM Sabah), Malaysia. She is now a member of the Institute of Marketing Malaysia (IMM) and Fellowship of the Australian Academy of Business Leadership. She has more than 26 years of experience in the academic and industry. Her areas of expertise are Brand Performance, Brand Management, Consumer Behaviour, and Marketing Management.

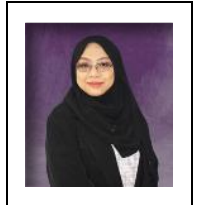

Sharifah Nurafizah Syed Annuar is a Senior Lecturer at the Faculty of Business and Management, UiTM Sabah, Malaysia. She received her PhD in Marketing from Universiti Malaysia Sabah in 2017 and currently serves as the Deputy Rector at Division of Research and Industry Linkages, Universiti Teknologi MARA (UiTM Sabah), Malaysia. With over 13 years of vast academic experience, its areas of specialization include Marketing Communications, Marketing Management, Consumer Behaviour, and Social Marketing.

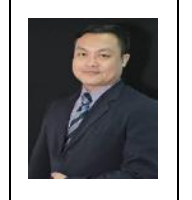

Nelson Lajuni is a Senior Lecturer at the Faculty of Business, Economics and Accountancy, University Malaysia Sabah (UMS). He received his DBA from Universiti Teknologi MARA (UiTM Sabah) in 2018. He has more than 15 years of vast academic experience; his areas of expertise are Behavioral Finance and Financial Management. He has in-depth knowledge of PLS-SEM and actively involved in the Sabah Research Group Society. 